\title{
VARIACIÓN MORFOSINTÁCTICA Y ENSEÑANZA DEL ESPAÑOL COMO LENGUA EXTRANJERA: REFLEXIONES DE UN LINGÜISTA METIDO A PROFESOR
}

\author{
Carlos Sánchez Avendaño
}

\begin{abstract}
RESUMEN
En este trabajo se realiza un examen crítico del tratamiento de la variación morfosintáctica de la lengua española en los libros de texto para su enseñanza como lengua extranjera. El propósito principal es elaborar algunos comentarios generales sobre la necesidad de considerar la heterogeneidad idiomática en las clases.

Palabras clave: Variación morfosintáctica, enseñanza, español como segunda lengua.
\end{abstract}

\section{ABSTRACT}

In this paper a critical revision about Spanish language morphosyntactic variation treatment is carried out from the textbooks published for its teaching as a foreign language. The main purpose is to state some general commentaries concerning the importance of considering the heterogeneity of the language in the classrooms.

Key words: Morphosyntactic variation, teaching, spanish, foreign languages.

\section{Introducción}

La enseñanza de segundas lenguas y lenguas extranjeras ha experimentado un desarrollo creciente en las últimas décadas en cuanto a concepciones, métodos, materiales, recursos e, incluso, aspectos históricos. No parece revelarse, no obstante, la misma producción intelectual

M.L. Carlos Sánchez Avendaño. Profesor de la Escuela de Filología, Lingüística y Literatura. Universidad de Costa Rica.San Pedro, San José, Costa Rica. 
en torno a la problemática de las variedades lingüísticas y su papel en la adquisición de la lengua y, sobre todo, su tratamiento en las clases de segundas lenguas.

Lo anterior no parece tan extraño si lo examinamos con la misma perspectiva historiográfica con la que se puede abordar el estudio de las ideas sobre la enseñanza-aprendizaje de los idiomas en general en Occidente, sean estos la lengua materna, un segundo idioma o una lengua extranjera. La idea tradicional acerca de la didáctica lingüística se ha centrado hasta época bien reciente ( $\mathrm{y}$, de hecho, todavía no se ha emancipado completamente) en el ideal de lengua de prestigio promovido por las élites sustentadoras del poder en los distintos periodos históricos y naciones (cfs. Robins 1997, de Beaugrande 2000).

Así, la famosa consigna de que existen formas "correctas" e "incorrectas" y, en un nivel más general, variedades "superiores" e "inferiores" de lengua sigue siendo lugar común en los medios de comunicación y en la mentalidad de la mayoría de los hablantes, especialmente los maestros. Ciertamente, si esta concepción de lengua homogénea e "incorruptible" continúa planteándose como la meta del aprendizaje escolar (así, sin matizaciones ni consideraciones de ningún tipo) en el caso del español como lengua materna, no parece raro que el asunto ni siquiera haya trascendido a la teorización sobre la didáctica de segundas lenguas, todavía preocupada por enseñar reglas infalibles como forma de facilitar el aprendizaje, en desmedro de la consideración de la naturaleza heterogénea y siempre variante de toda lengua.

La cuestión no parece tener una solución fácil. No solo son los profesores de idiomas, quienes muchas veces reproducen estas ideas acientíficas y simplonas acerca de la lengua, encubriendo su profundo desconocimiento sobre el objeto que enseñan, sino que muchas veces los mismos aprendices llegan a un lugar con la expectativa de aprender el "español correcto", la forma "verdadera" de decir las cosas. John Lipski (1994: 154) nos lo indica claramente:

\begin{abstract}
No es raro oír comentarios, proferidos por igual por hispanoamericanos y por españoles, sobre una ciudad, provincia o país donde se habla el español 'más puro'. Los miembros de las clases sociales más bajas, o que viven en regiones cuya habla es considerada 'pintoresca' por sus compatriotas, denigran su lengua y lamentan no hablar 'buen español'. Los estudiantes extranjeros, de Estados Unidos y de otras partes, al empezar sus clases de español, preguntan si están aprendiendo una forma 'correcta' de español y, si es así, cuál es su pedigrí.
\end{abstract}

El presente trabajo consiste en una reflexión sobre la problemática de la inclusión o exclusión de la heterogeneidad de la lengua española (especialmente la diversidad de índole geográfica, aunque también se hablará de la variación social y de registro) en los libros de texto y, en general, en las clases de español como lengua extranjera o como segunda lengua. Por razones de claridad expositiva, hemos decidido centrarnos en algunos puntos muy concretos de la variación dialectal, en el nivel de la morfosintaxis, por medio del análisis de veinte libros de texto publicados en los Estados Unidos ${ }^{2}$, casi todos desde la década del noventa; todo ello a partir de algunas investigaciones cuyos resultados sobre variación dialectal, social y estilística nos permitan elaborar una crítica sólida.

El hecho de haber seleccionado como objeto principal de este estudio los libros estadounidenses requiere una justificación. En primer lugar, es bien sabido que en dicho país la enseñanza del español se ha extendido a casi todos los niveles educativos y que, por su potencial editorial, se publican constantemente libros de texto que, en principio, responden a las nuevas tendencias teóricas y metodológicas para la didáctica de lenguas extranjeras. En segundo lugar, nuestra experiencia como profesores de español como segunda lengua en Costa Rica nos ha permitido observar el empleo de muchos de estos libros - ya sea en su totalidad (como 
libros de texto de los cursos) o en forma parcial (utilizando únicamente las prácticas, las actividades o partes de las secciones de explicación gramatical, por ejemplo)— en universidades e instituciones que cuentan con programas para la enseñanza del español a hablantes no nativos. Suponemos que esta práctica no ha de ser muy distinta en otros países de habla hispana; sus implicaciones las comentaremos al final del presente trabajo.

Además, es necesario aclarar que mantenemos aquí la distinción teórica entre segundas lenguas y lenguas extranjeras, pues consideramos que es relevante para los propósitos de este ensayo. En los trabajos de glosodidáctica, la lengua extranjera es cualquier lengua que no sea la lengua nativa en un país y que se enseñe en ámbitos escolares; por lo general, no se usa como medio de comunicación cotidiana en el país en el que se aprende (por ejemplo, el francés en Costa Rica). Por su parte, una segunda lengua se aprende en un lugar en el que sí es el instrumento de interacción diaria (por ejemplo, el español en México para un holandés).

\section{La variación lingüística en los libros de texto}

En los libros de texto examinados en este artículo, rara vez se hace alusión a la diversidad lingüística en las explicaciones gramaticales, léxicas o de pronunciación correspondientes como parte de la teoría que se estudia; más bien, se menciona — si es que se realiza— en notas al pie de página o al margen para el estudiante y, más comúnmente, en notas para el profesor.

Algunos libros incluyen una sección dedicada, entre otros asuntos, a aspectos de variación: Puntos en breve trata de rescatar, en particular, el aporte que puedan realizar los hijos de hispanohablantes nativos residentes en los Estados Unidos en las secciones "Heritage Speakers", por lo que constantemente impele al profesor a tomarlos en cuenta en la clase y sacar provecho de su presencia. Por su parte, Plazas incluye, en las notas “¿Nos entendemos?", información sobre la diversidad del español, sobre todo en el nivel léxico. La misma función cumplen las notas “Sabías?” del método Spanish for life y "Las palabras viven” de Dos mundos. En los demás libros, la mención a aspectos de diversidad idiomática constituye más bien una rara excepción.

En todo caso, para este trabajo interesa no solamente analizar la mención explícita a elementos de variación lingüística hispánica, sino, sobre todo, observar cómo se tratan determinados aspectos idiomáticos en cuyos casos la variación es particularmente notable o está ampliamente estudiada. Asimismo, nos interesa destacar los casos en los que se incluyen en los libros formas en desuso en el español hablado contemporáneo, o cuando no se hace la referencia más que necesaria a la pertenencia de determinado rubro de la lengua a un registro (oral o escrito), a un estilo (formal o informal) o a una región geográfica concreta.

\subsection{La variación morfosintáctica}

A pesar del auge del enfoque comunicativo, lo cierto es que la enseñanza de la morfosintaxis (sea de forma explícita o implícita) continúa siendo uno de los pilares de las clases de lenguas extranjeras y segundas lenguas.

Siendo así, parece fundamental llevar a cabo un análisis de la presentación didáctica de este componente de la lengua en lo concerniente a la variación idiomática que lo caracteriza, a pesar de la idea común entre especialistas de que se trata del nivel lingüístico en el que se halla 
menos variación, sobre todo si se compara con el léxico o la fonética (Moreno de Alba 1993). Quizás precisamente por esta misma concepción, no se le ha prestado la suficiente atención en la enseñanza ni, mucho menos, en la elaboración de gramáticas descriptivas y pedagógicas (De Kock y DeMello 1997).

Examinemos algunos casos particulares: las formas de tratamiento, las formas verbales (el futuro simple de indicativo, el pretérito perfecto compuesto de indicativo y el pretérito imperfecto de subjuntivo), las cláusulas hipotéticas en pasado irreal, los pronombres (de objeto directo e indirecto y los relativos) y los determinantes (posesivos y demostrativos).

\subsubsection{Las formas de tratamiento}

En cuanto a las formas de tratamiento, nos encontramos con tres aspectos llamativos: la omnipresencia de 'vosotros' en prácticamente todos los libros, la ausencia de 'vos' en la gran mayoría y la presentación de 'tú' y 'usted' con una caracterización pragmática específica que se generaliza a todo el mundo hispanohablante.

Con la excepción de Caminos, todos los textos analizados presentan, dentro del cuadro de pronombres personales y luego en los demás paradigmas pronominales y en los de conjugación verbal, la forma 'vosotros'. Se dice en ellos, normalmente en una nota al margen, que este pronombre, y su respectiva conjugación, se emplea únicamente en España o "casi toda" España como la forma plural de 'tú', sin siquiera aclarar en cuáles partes de la Península no se encuentra. Este fenómeno resulta todavía más llamativo cuando se considera el público meta al que van dirigidos estos libros: los estudiantes de secundaria y universidad de Estados Unidos, normalmente más cercanos a Hispanoamérica que a España en cuanto a intereses comerciales y sociales (la gran mayoría de los inmigrantes hispanohablantes en esta nación son del continente americano).

Con la misma vaguedad con que se menciona que en "casi toda" España se usa el 'vosotros', algunos de estos libros refieren que "en casi toda" la América hispanohablante se emplea solamente la forma 'ustedes' como plural de 'tú' y de 'vos' (Dicho y hecho, ;Arriba!), con lo cual se da a entender que existen regiones en las que no es así. Nuevamente, la inespecificidad de tal afirmación deja muchas dudas, sobre todo cuando -hasta donde tenemos conocimiento- ningún dialectólogo ha dado noticias de regiones hispanoamericanas en las que se encuentre 'vosotros' en habla espontánea, sino que, por el contrario, los manuales de dialectología hispanoamericana suelen afirmar con total certeza que el tratamiento 'vosotros' (y su respectiva conjugación) referido a un interlocutor plural no existe en la región (Vaquero 1998: 28) o se encuentra circunscrito a situaciones comunicativas concretas de reducido uso social ${ }^{3}$.

Por lo general, no se dan razones para la inclusión de 'vosotros' en estos textos o, a lo sumo, se menciona que es importante que los estudiantes reconozcan las formas, probablemente debido a que es posible que realicen en algún momento un viaje a España (p.e. Dicho $y$ hecho, En Contacto); es decir, se pretende que los aprendices alcancen una competencia pasiva, hecho que se evidencia en la ausencia de prácticas que exijan su uso. Este razonamiento resultaría válido si los autores fueran coherentes con su propuesta, esto es, si consideraran constantemente la posibilidad de que los alumnos entren en contacto con variedades de uso más restringido que las estudiadas en los libros, para lo cual sería necesario que estén preparados, teniendo conocimiento al menos de la existencia de estas. 
Sin embargo, el argumento se vuelve endeble cuando constatamos que se excluye la mención, por lo menos en notas al margen, del voseo. ¿Cómo se puede explicar esta omisión? ¿Será ignorancia de los autores o un prejuicio insostenible que los lleva a dejar por fuera esta forma? Lamentablemente, es probable que ambas explicaciones sean plausibles.

La forma 'vos' únicamente está presente en seis de los libros analizados: Caminos, ¡Arriba!, Puntos en breve, Spanish for life, ;Ven conmigo! y Dos mundos, como una nota al margen y nunca en los cuadros de conjugación verbal. En Caminos, en una nota para el profesor, se especifica que el voseo se utiliza en Argentina, Costa Rica, Paraguay, Uruguay y otros lugares de América Latina. ¡Arriba! consigna la existencia del voseo en Costa Rica, Argentina, Uruguay, partes de Colombia y otras regiones hispanoamericanas, como un sustituto de 'tú'; no obstante, en el capítulo en que se habla de estos países, los diálogos no hacen uso del voseo.

También en Spanish for life se incluye en el capítulo ambientado en Argentina una referencia al margen sobre el 'vos' como sustituto de 'tú'; en la nota para el profesor se aclara en cuáles países se encuentra el fenómeno: en América del Sur (Argentina, Uruguay, Paraguay, partes de Bolivia, Chile, Ecuador, Colombia y Venezuela) y Centroamérica (con exclusión de Panamá), y para ejemplificar incluye dos oraciones: "La gente dice: ‘Cómo estás vos? Vos hablás muy bien el español'”(Brown 2000: 257). Además de la obvia artificialidad de los ejemplos (se incluye el pronombre únicamente para hacer más evidente lo "exótico" de la construcción), el afirmar que el pronombre 'vos' es un sustituto de 'tú' lo coloca en un nivel de suplencia, como si se tratara de una forma alternativa a la original y no -como lo es en realidad- como un elemento equivalente en cuanto a la referencia deíctica (se emplea con un interlocutor singular).

Quizás sea en Puntos en breve en donde encontramos el tratamiento más innovador al respecto. En una nota para el profesor, los autores recomiendan:

\footnotetext{
Si hay hispanohablantes en su clase que usen o estén familiarizados con el voseo (por ejemplo, que digan vos sos, vos hablás, vos vivís), pídales que le expliquen a la clase la diferencia entre tú, Ud. y vos y que den ejemplos del voseo. Si desea ampliar esta actividad, pídales a dos estudiantes hispanohablantes que lleven a cabo una breve conversación (quizás representando los papeles de amigos que se encuentran en la calle). Luego, invite a dos otros (sic) a repetir la misma conversación usando el voseo (Pérez-Gironés 2002: 40).
}

Evidentemente, la limitante de este ejercicio reside en la sujeción a la presencia en la clase de hispanohablantes que voseen y a la decisión del profesor de tratar este aspecto. Seguidamente, el mismo libro le solicita al docente que les recuerde a los alumnos que 'vos' se usa en lugar de 'tú' en algunos países (Argentina, Uruguay y Costa Rica; en la página 267 agrega a la lista Colombia y Ecuador), y, en la lección sobre el imperativo, recomienda incluir en la explicación y las actividades las formas de 'vos'.

Dos mundos es el único de los libros de texto examinados que presenta las formas de conjugación propias del voseo monoptongado, en notas al pie de página distribuidas a lo largo de todos los capítulos que incluyen cuadros de conjugación ${ }^{4}$. Sin embargo, es bastante vago en la mención de las regiones voseantes (dice que se encuentra en algunos lugares de América Latina, incluyendo Argentina y Centroamérica) y aclara inmediatamente: "Todo el mundo que

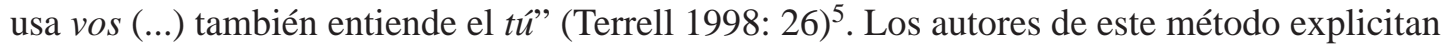
las razones para esperar tan solo una competencia pasiva en cuanto al voseo y a 'vosotros': "Los pronombres regionales vos y vosotros no aparecerán en los ejercicios y actividades de 
Dos Mundos porque usted los aprenderá rápidamente si viaja a regiones donde se usan con frecuencia" (Ibídem). Sin embargo, como se vio anteriormente, los paradigmas de 'vosotros' se hallan junto a los de las demás formas pronominales, mientras que los de 'vos' se incluyen en notas al pie de página, lo que de hecho revela una jerarquización tipográfica relativa a la importancia de una forma frente a la otra.

Creemos que 'vosotros' se incluye en estos libros por un asunto de tradición que marca esta forma como prestigiosa (está respaldada por la literatura clásica española), como perteneciente a la variedad de español considerada como el ideal de lengua. Esta noción, indiscutiblemente aún presente en la actitud de muchos puristas y personas comunes, es la misma que hace incluir en los paradigmas verbales que se enseñan en la escuela en muchos países hispanoamericanos las formas de 'vosotros' y a excluir las de 'vos' en los países o áreas voseantes ${ }^{6}$.

El tercer aspecto anunciado, la generalización extrema acerca de los usos de 'tú' y 'usted', no es menos merecedora de nuestra atención. Elaborando una sinopsis de las explicaciones que se consignan en los textos, 'tú' se utiliza en el trato informal o familiar con gente con quien se emplearía el nombre de pila/gente a la que se conoce bien, con amigos, personas de la misma edad o posición social, compañeros de estudio, colegas, niños, parientes y mascotas. Por su parte, 'usted' se usa en el trato formal o respetuoso con gente con quien se usaría el apellido/gente a la que no se conoce bien, desconocidos (excepto niños), personas no muy cercanas o en puestos de autoridad, gente mayor que el hablante, vendedores y en el trato de hijos a padres. Todas estas explicaciones se presentan con un valor absoluto; en otras palabras, se afirma que ese es el uso, sin matizaciones ni comentarios de ninguna clase, como cuando en Gente se asevera que "a los niños siempre se les tutea" (Martín Peris 2003: 157).

En Gente se agrupan todos estos elementos en factores: a) el grado de conocimiento y familiaridad, b) la jerarquía y c) la edad, y se aclara que todos ellos "se combinan e interrelacionan de modo que la casuística es bastante compleja” (Martín Peris 2003: 157). Aparte de esta declaración de que, efectivamente, el fenómeno es más complicado de lo que las simples recetas con fines pedagógicos -esperamos- dejan ver, es nuevamente en Puntos en breve en donde al estudiante se le dice:

\footnotetext{
(...) en general, tú se usa para referirse a amigos cercanos o a miembros de su familia, mientras que usted se usa con gente con la que el hablante tiene una relación más formal o distante. Las situaciones en las cuales tú y usted se usan también varían entre los diferentes países y regiones (Pérez-Gironés 2002: 40).
}

En este último punto insisten los autores más adelante, en una nota para el profesor, en la cual le piden al docente enfatizar la diferencia entre ambas formas y señalar que sus contextos de uso difieren mucho entre los países hispanohablantes y las generaciones: "En algunos países (por ejemplo: España, Puerto Rico y Cuba), la gente es mucho más liberal en cuanto al uso de tú que en otros (por ejemplo: Colombia, Honduras o Costa Rica)" (Ibídem) ${ }^{7}$.

Exceptuando los libros mencionados, es evidente que la gran mayoría de los autores de estos textos generalizan en extremo las reglas pragmáticas de empleo de las formas de tratamiento 'tú' y 'usted'. Efectivamente, tal como responsablemente se hace en Puntos en breve, lo que se debe presentar es un modelo práctico y básico del uso de tales formas, pero, a la vez, se debe dejar en claro que existen variedades dialectales y sociolectales en las que no se aplican tan tajantemente las distinciones reseñadas. También habría que resaltar la aclaración que 
se realiza en, por ejemplo, Plazas, acerca del uso que comúnmente se hace en Colombia de la forma 'usted' referida a, incluso, amigos.

Como afirma Quesada Pacheco (2000a: 89-90),

(...) al margen del uso de vos o tú como tratamiento en el plano de la solidaridad, se asoma usted con el mismo valor en regiones como Honduras, Costa Rica, Panamá (zona occidental, donde convive con vos), Colombia, Venezuela, Bolivia (Oriente), Argentina (noroeste) y Chile (...). En las regiones donde se emplea hay una neutralización pronominal, de manera que usted vale tanto para el plano de la solidaridad como del distanciamiento, y se utiliza para todo tipo de personas y en cualquier situación.

Este mismo lingüista nos aclara que las situaciones difieren mucho de región en región: en Honduras, esta neutralización es propia de zonas rurales o en situaciones de enojo, como también sucede en El Salvador; en regiones de Bolivia implica la idea de afecto entre padres e hijos; en Buenos Aires se usa con los niños; en Chile se emplea con los hijos y entre los cónyuges; en Costa Rica, "se da entre parientes y no parientes, entre urbanos y rurales, en el trato cariñoso y cuando se está enojado o contento. Es también el tratamiento que se da a los animales" (Ibídem).

En otras palabras, en muchas regiones del mundo hispanohablante, las reglas consignadas en los textos analizados no describen la realidad de uso. El problema no está en la exposición simple y básica, con una clara finalidad didáctica indispensable sobre todo en los niveles más elementales, sino en la generalización en términos absolutos del tipo "siempre es asî”, "nunca se usa", "siempre se emplea", con lo cual se le hace creer al discente que las formas y usos estudiados son los únicos esperables o, peor aún, los únicos legítimos. Ya está visto que ni siquiera se debe generalizar que a los niños y a las mascotas siempre se les tutea, pues para ambos casos existen áreas en donde no es así.

En una actividad como la que se presenta en Dos mundos, en la que se le pide al estudiante que decida cuál forma de tratamiento emplear ('tú' o 'usted') cuando habla con, por ejemplo, un amigo de la universidad o una niña de diez años, es obvio que, si lo que se pretende es que escoja la forma apropiada que utilizaría un hablante nativo, el aprendiz va a elegir la que se ajuste a los parámetros dados en el libro y, muy probablemente, creerá que eso debe ser así en cualquier región hispanohablante. Se llevará una gran sorpresa cuando escuche que, por poner un caso, un costarricense de su misma edad le ustedee a su amigo universitario, a la niña y -lo que será aún más impactante- a su perro ${ }^{8}$.

La enseñanza de las formas de tratamiento en español no es, a todas luces, una cuestión fácil de resolver, sobre todo cuando lo que entra en juego es mucho más que la simplificación pedagógica: existen prejuicios infundamentados; criterios puristas anacrónicos; prestigios elaborados a partir de nociones elitistas de la lengua (como el de que la formas literarias tienen mayor valor que las coloquiales); desconocimiento de la variación dialectal, sociolectal y estilística de la lengua; concepciones equivocadas sobre "lo estándar" y, por lo tanto, "lo enseñable". Todos estos factores confabulan en contra de argumentos más válidos, tales como el estadístico (hay más personas voseantes que las que utilizan la forma 'vosotros'), la previsión de situaciones comunicativas distintas a las estudiadas en clase (existen tantas posibilidades -si no es que más- de que un estudiante de español viaje a un país o región voseante como las hay de que viaje a España), o la sinceridad y responsabilidad didácticas (es lícito centrarse en el estudio y práctica de unas formas determinadas, pero jamás lo es negar la existencia de otras formas o usos). 


\subsubsection{Los 'tiempos'verbales}

Los llamados "tiempos verbales"9 representan el tema gramatical estrella en las clases y los libros de texto de español como lengua extranjera (y como segunda lengua). Tres son las formas que deseamos destacar aquí: el pretérito perfecto compuesto de indicativo, el futuro de indicativo y el pretérito imperfecto de subjuntivo ${ }^{10}$.

En cuanto al pretérito perfecto compuesto, el principal problema lo encontramos en la explicación de uno de sus usos (normalmente el primero que se expone y ejemplifica): este tiempo se usa para denotar un pasado reciente o inmediato, como en el siguiente ejemplo: "He roto mi compromiso con Juan y estoy saliendo con Miguel" (Ascarrunz 1993: 160).

En Dicho y hecho no se habla de eventos ocurridos en un pasado reciente, pero sí de acciones cuyas consecuencias se sienten en el presente, para lo cual dan los siguientes ejemplos: ¿Has comido?” y "He terminado el proyecto”, casos claros del llamado pasado reciente. Spanish for life lo consigna para la expresión de una acción completa en el pasado reciente, pero cuyos efectos continúan en el presente: "Ya he comido", "Me he levantado tarde".

En Caminos (Renjilian-Burgy 1999: 381), por su parte, no se dan explicaciones sobre el uso de esta forma verbal, pero por los ejemplos no queda totalmente claro si se trata de un pasado reciente o del aspecto durativo, como se puede notar en el siguiente fragmento de un diálogo:

TOMÁS: ¿Qué has hecho hoy, Mario?

MARIO: He tenido un día muy bueno. He trabajado en mi proyecto sobre el medio ambiente, he ido a la tienda de comestibles y he cocinado una cena muy sabrosa para mi novia.

En ninguno de los libros analizados se menciona la diferencia de uso de esta forma verbal en los distintos dialectos del español. Su valor en cuanto a evento limitado al pasado (normalmente un pasado reciente) es propia de España y los países andinos (Perú y Bolivia), pero no del resto de Hispanoamérica, en donde posee un valor aspectual durativo o denota un evento pasado que se proyecta o continúa hasta la actualidad (Quesada Pacheco 2000a, DeMello 1997). En suma, en el español peninsular, la oposición entre el pretérito simple y el compuesto es temporal, mientras que en el español hispanoamericano es, generalmente, de tipo aspectual (Moreno de Alba 1993).

De este modo, los ejemplos citados se considerarían empleos atípicos en gran parte del mundo hispanohablante, aunque no -de ninguna manera- ilegítimos. Otra vez, el problema se debe a una excesiva generalización o un desconocimiento profundo de la variación idiomática ${ }^{11}$.

Así, para México, Lope Blanch (2000) afirma que el pretérito perfecto simple indica un acontecimiento perfectivo y puntual, mientras que el compuesto denota uno imperfectivo o reiterativo; para este linguiista, la distancia temporal en relación con el momento de la enunciación no tiene relevancia para la elección de una u otra forma, como sí sucede en la norma castellana. Por su parte, en lo concerniente a los llamados tiempos de pretérito, De Kock (1997) llama la atención hacia el hecho del menor porcentaje de uso del perfecto compuesto en el habla culta de ocho ciudades hispanoamericanas (Buenos Aires, Bogotá, Caracas, Lima, México, Santiago de Chile y San Juan de Puerto Rico) frente al habla culta de Madrid ${ }^{12}$. En lengua literaria, la diferencia es aún más notoria entre América $(9,11 \%$ de empleo de esta forma frente al pretérito simple y el imperfecto) y España $(39,37 \%)$. 
Quesada Pacheco (2000b) consigna para Centroamérica el uso del pretérito simple para cualquier tipo de acción pasada, y el compuesto para acciones pasadas proyectadas hasta el presente ("He estado enfermo desde el lunes") o para el énfasis o topicalización de una acción pasada ("Venía distraído por el camino y me he tropezado con un caballo"). En Venezuela, Sedano y Bentivoglio (2000) aseguran que el pretérito simple se emplea para acciones concluidas, sean recientes o muy anteriores, mientras que el compuesto sirve para expresar una situación no concluida del todo o con relevancia presente ("Siempre me ha gustado viajar”). Por último, para Argentina, Donni de Mirande (2000) manifiesta que en la zona litoral-pampera se prefiere el pretérito simple, pero que en la región central se emplea más el compuesto. Para este mismo país, Lipski (1994) señala que el pretérito simple se suele usar, en vez del compuesto, en situaciones en las cuales es clara la continuidad en el presente: "Juan no llegó todavía".

Con respecto al futuro de indicativo (el futuro sintético), cabe observar que todos los textos lo presentan como un alternante de la perífrasis 'ir a + infinitivo' (el "futuro informal”, según Dos mundos) o como una forma que se refiere a un futuro más lejano que el indicado por esta. También se le denomina el "verdadero futuro" (Contigo), a pesar de que es un hecho más que documentado de que se trata de una forma poco frecuente en la conversación espontánea con este valor (Quesada Pacheco 2000a, Moreno de Alba 1993, Lope Blanch 1970, los diferentes apartados en Alvar 2000). Por ejemplo, para el habla culta de México, Moreno de Alba (1977b) nos da los siguientes porcentajes para las formas verbales con valor de futuro absoluto: 'ir a + infinitivo': $51 \%$, presente de indicativo: $25,8 \%$, futuro sintético: $23,2 \%$.

Esta forma se utiliza, especialmente, en el registro escrito ${ }^{13}$ con valor de futuro, y en el oral con el valor modal de conjetura, inferencia, probabilidad o dubitación con respecto al presente; es decir, en este segundo caso no se trata de un "verdadero futuro". Desgraciadamente, solamente en Dicho y hecho y en Dos mundos se especifica, en una nota, que su uso es menor que el de 'ir a + infinitivo' con el sentido de futuro. Hay que reconocer que, por lo menos, varios de los textos examinados incluyen el valor modal dentro de sus empleos (Dicho y hecho, Charlemos un poco, ¡Arriba!, Horizontes, Dos mundos).

Por último, el pretérito imperfecto de subjuntivo también es tema de variación en español; en particular, el hecho de que posee dos alomorfos, en apariencia, en variación libre: -ra -se. Empero, aunque el empleo de una forma o la otra no conlleve cambio de significado, el uso está determinado por motivos dialectales y estilísticos. Todos los libros estudiados consignan el paradigma respectivo con la forma -ra y, algunos, anotan que -se es otra posibilidad, sin aclarar en qué lugar o situación (Caminos, ;Claro que sí!), o afirman que se oye únicamente en España (Plazas, Así es, Horizontes, En Contacto). En Charlemos un poco, se dice que la forma con -se es menos frecuente y se encuentra en partes de América Latina y España.

El hecho de que en Hispanoamérica prevalecen las formas en -ra no se pone en duda (Quesada Pacheco 2000, Vaquero 1998, Alvar 2000), pero la afirmación de que se utiliza más en España es ya un lugar común entre los profesores de español como segunda lengua. Desafortunadamente, se trata de un dato erróneo: tanto en España como en América, la forma en -ra supera en frecuencia de uso a la forma en -se. En España, los estudios de habla culta de Madrid y Sevilla consignan un porcentaje de $85 \%$ de uso de -ra frente a -se (DeMello 1997). Además, no está claro que sea generalizable tampoco el dato de que en toda Hispanoamérica prevalecen las formas en -ra, sobre todo en vista de que el factor 'grado de formalidad del discurso' no ha sido estudiado a profundidad a este respecto ${ }^{14}$. 
En este mismo apartado, vale la pena analizar la estructura que se presenta para las cláusulas hipotéticas en pasado irreal. De los cuatro libros que incluyen este tema, solamente uno (Horizontes) da como alternantes en igualdad de condiciones las construcciones ' $\mathrm{Si}+$ pluscuamperfecto de subjuntivo + condicional perfecto' y ' $\mathrm{Si}+$ pluscuamperfecto de subjuntivo + pluscuamperfecto de subjuntivo'. En los otros tres, En contacto, Dos mundos y Charlemos un poco, se describe únicamente la primera posibilidad: "Si hubiera ganado las elecciones, el candidato habría hecho varios cambios para mejorar la situación económica" (Terrell 1998: 540).

El dato es relevante cuando se sabe que el uso del pluscuamperfecto de subjuntivo en el resultado (la apódosis) en lugar del condicional perfecto es general tanto en España como en Hispanoamérica: en el habla culta de varias ciudades importantes de las dos regiones prevalece en hasta un $90 \%$ por sobre el empleo del condicional (DeMello 1997). ¿Por qué privilegiar, entonces, la construcción menos frecuente en desmedro de la más utilizada?

Además, afirmaciones como la que se hace en Dos mundos (Terrell 1998: 540) sobre la poca frecuencia de uso cotidiano de este tipo de cláusulas con pluscuamperfecto de subjuntivo ("Estas formas no se oyen frecuentemente en la conversación ordinaria, pero son comunes en la escritura y el habla más formal") resultan inexactas y basadas en una impresión difícilmente corroborable.

\subsubsection{Los pronombres relativos y de objeto}

En cuanto a los pronombres relativos, el aspecto que inmediatamente salta a la vista al examinar los libros de texto concierne a las explicaciones sobre el uso de 'que' y 'quien' y, en menor medida, 'el cual'. La mayoría de los textos se limitan a indicar cuáles son los distintos pronombres relativos y su uso según los condicionamientos sintácticos ('quien' se usa en cláusulas no restrictivas y después de preposición) y semánticos ('quien’ se refiere a personas, mientras 'que' puede referirse también a animales y cosas). En Repase y escriba se afirma que el relativo 'que' es más común en el registro oral y Horizontes señala que simplemente se usa más, sin mayores detalles. Es de lamentar, por consiguiente, la ausencia de explicaciones más detalladas y exactas sobre este aspecto morfosintáctico, sobre todo cuando se piensa que, para este punto, la mayoría de los estudiantes ya ha superado el nivel elemental de manejo de la lengua.

Como lo hace ver De Kock (1997), la cuestión del empleo de un relativo u otro no solamente está determinada por los condicionamientos señalados, sino, especialmente, por el registro empleado; en su estudio de las variedades madrileñas, este autor encuentra que el relativo 'que' supera con creces la frecuencia de uso de 'quien' y 'el cual' en la escritura, y que estos últimos están casi ausentes en el habla espontánea culta (seis apariciones de 'quien' y una de 'el cual', frente a 379 de 'que' y 218 de 'el que'). Para Costa Rica, Solano Rojas (1990) encontró el predominio casi absoluto del nexo 'que' (98,98\%) sobre los otros relativos (cual, quien, donde, cuando, como, cuanto) y otras formas nexuales en el habla culta. En un estudio de nuestra autoría sobre los mismos materiales del habla culta costarricense, de 177 cláusulas de relativo, únicamente seis emplearon un pronombre distinto a 'que'; es decir, como relativo, 'que’ se utilizó en un 96,61\% de los casos (Sánchez Avendaño 2001).

Mención aparte merece el relativo 'cuyo', tratado en tres de los libros: Repase y escriba, En Contacto y Charlemos un poco. En ninguno de ellos se menciona que se trata de una forma 
en desuso en el español moderno oral de todas las regiones (Quesada Pacheco 2000); por ejemplo, Solano Rojas (1990: 201-2) únicamente halló un caso de ‘cuyo’ en el habla culta costarricense, en un discurso formal de una persona que ocupó altos puestos públicos, razón por la cual esta lingüista afirma que este elemento no forma parte del habla de Costa Rica. De Kock (1997) no lo encontró ni una sola vez en los materiales para el estudio del habla culta de Madrid, pero sí en textos de prosa informativa.

Pese a su desuso, los tres libros de español mencionados lo incluyen como un relativo más, sin especificar que es propio del registro escrito formal y de ninguna manera un equivalente exacto del inglés 'whose', como lo consigna Repase y escriba: "Los jóvenes cuyos padres beben, tienen muchos problemas" (Canteli 1998: 410).

Constituye un grave error, entonces, que los libros de texto no mencionen la diferencia implicada en el uso de los pronombres relativos según se esté hablando o se esté escribiendo, con lo que quizás se podrían evitar fosilizaciones de fenómenos de divergencia lingüística en el caso de los anglohablantes que aprenden español, los cuales comúnmente utilizan el relativo 'quien' cuando producen cláusulas restrictivas referidas a seres humanos.

En lo concerniente a los pronombres de objeto directo e indirecto, salta a la vista la total concordancia de los libros estudiados: el paradigma que se enseña es el etimológico. De hecho, el uso de 'lo, la, los, las' como pronombres de objeto directo y de 'le, les' en función de objeto indirecto es el único que se muestra en la mayoría de los libros examinados (Charlemos un poco, Plazas, Así es, Caminos, Dicho y hecho, ¡Ven conmigo! y Spanish for life). Sin embargo, varios incluyen, asimismo, una referencia sucinta al empleo de 'le, les' en función de complemento directo relativo a hombres en España (Contigo, En contacto, Dos mundos, Puntos en breve, Horizontes) y relativo a personas en regiones de América Latina (Puntos en breve, Horizontes), sin especificar de cuáles áreas en concreto se trata.

Efectivamente, el leísmo es propio del centro y norte de España, pero se ha consignado para algunas regiones hispanoamericanas: el Caribe, Bolivia y Ecuador (Vaquero 1998), en el español andino de Perú (Caravelo 2000), en Paraguay dentro del habla coloquial y con referente de persona (Garrido 1992), y en ciertos contextos en Costa Rica y Uruguay (Quesada Pacheco 2000). Si bien, DeMello (1997) hace ver que las circunstancias en las que se utiliza 'le' o 'lo' pueden ser más complejas de lo que normalmente se dice, como en el caso de su uso con el verbo 'enseñar'.

\subsubsection{Los determinantes: demostrativos y posesivos}

En cuanto a los determinantes demostrativos, es absoluta la presencia del paradigma tripartito, acompañado de la explicación relativa a la distancia con respecto a los hablantes: 'este' (cerca del hablante), 'ese' (cerca del oyente, a cierta distancia del hablante, a una distancia corta, 'nearby'), 'aquel' (lejos del hablante y del oyente, a una gran distancia, 'over there'): ¡Arriba!, Dicho y hecho, Caminos, Contigo, En Contacto, Dos mundos, Horizontes, Puntos en breve. En Charlemos un poco, se presenta también este paradigma, pero simplemente se dice que 'este' indica lo más cerca del hablante y 'ese' y 'aquel', la noción de lejanía.

La tendencia anterior a incluir este sistema de tres miembros la explica con maestría José De Kock (1997:14): 
Sabido es que en español existen tres pronombres demostrativos: este, aquel y ese, que se hacen corresponder, a grandes rasgos, con tres modos señalativos, cerca, lejos, entre los dos, más o menos paralelos, a su vez, con las tres personas verbales: primera, tercera y segunda. Estamos ante un hermoso esquema, con el que las gramáticas españolas están muy encariñadas porque el español es, en esta circunstancia, reflejo del latín, lo que la mayoría de las lenguas colindantes y emparentadas no pueden pretender. Y sin embargo, de la teoría al empleo efectivo hay más que un trecho y entre el registro escrito y el hablado media un abismo.

Spanish for life aclara en una nota que en América Latina la tendencia es utilizar 'este' y 'ese' mucho más que 'aquel'; por el contrario, los españoles dicen más 'este' y 'aquel', pues para ellos 'ese' conlleva un sentido peyorativo. Según el estudio de De Kock (1997), esta afirmación resulta falsa. Sólo para el habla culta madrileña, este lingüista encontró que, efectivamente, se usan predominantemente dos formas con valor demostrativo distintivo: 'este' y 'ese', el segundo mucho más frecuentemente que el primero ('ese': 270 apariciones, frente a 'este': 120, y aquel: 19). En el registro escrito, a partir del análisis de un corpus de 19 textos, el mismo autor halló una diferencia notable: también se usan, sobre todo, dos demostrativos, pero en este caso se trata de 'este' y 'aquel', mientras que 'ese' aparece en forma neutra ('eso') con antecedentes imprecisos o en locuciones (p.e. 'por eso') o en un valor como el de 'este' 15 .

Aunque desconocemos la existencia de estudios sobre este tema en las variedades hispanoamericanas, el sistema -al menos para algunas regiones- parece ser bipartito: 'este' (+cercanía del hablante) y 'ese'/'aquel' (-cercanía del hablante). En todo caso, lo que salta a la vista en este caso particular es la necesidad de incorporar la distinción entre formas más comunes del registro oral frente a las más usuales en el escrito; además, llama la atención el ceñimiento tan evidente de estos libros de texto a las descripciones gramaticales tradicionales del español, aun cuando estas sean inexactas, anacrónicas o extremadamente generales.

Los adjetivos y pronombres posesivos nos muestran, de la misma manera, la confusión entre formas propias de un registro o área geográfica que se explican sin aclarar su extensión. El caso extremo de generalización está representado por Caminos, en cuyo caso se incluyen las formas 'su, sus' sin indicar nada más que su traducción al inglés. Por lo general, los demás libros incluyen un paradigma como el siguiente:

\section{Cuadro 1: Adjetivos posesivos}

\begin{tabular}{|l|l|}
\hline \multicolumn{1}{|c|}{ Pronombre personal } & \multicolumn{1}{c|}{ Posesivo antepuesto } \\
\hline yo & mi, mis \\
\hline tú & tu, tus \\
\hline él/ ella / usted & su. sus \\
\hline nosotros / as & nuestro / a, nuestros / as \\
\hline vosotros / as & vuestro / a, vuestros / as \\
\hline ellos / ellas / ustedes & su, sus \\
\hline
\end{tabular}


Al lado de este sistema, todos los libros examinados incluyen al margen una indicación sobre la posible ambigüedad de las formas 'su, sus' en cuanto a la identidad del poseedor, solucionada usualmente por el contexto o, si no, aclarada por medio de la fórmula 'de + sustantivo o pronombre': "Es su libro. El libro es de Paco" (Zayas-Bazán 2001: 88). Sin embargo, De Granda (1978) muestra que, para el español atlántico (concepto que incluye a las hablas hispanoamericanas, canarias y meridionales de la Península), la pérdida de 'vosotros, vuestro’ del paradigma pronominal-posesivo provocó una reestructuración en el sistema total, de tal forma que el sistema de posesivos en muchas variedades habladas del español sería el siguiente:

Cuadro 2: Formas posesivas del español atlántico

\begin{tabular}{|l|l|}
\hline \multicolumn{1}{|c|}{ Pronombre personal } & \multicolumn{1}{c|}{ Posesivo antepuesto } \\
\hline yo & mi, mis \\
\hline tú / vos & tú, tus \\
\hline él/ella & de él/de ella \\
\hline usted & su, sus \\
\hline nosotros & de nosotros / as \\
\hline ellos / ellas & de ellos / de ellas \\
\hline ustedes & de ustedes \\
\hline
\end{tabular}

Lo más notable de este sistema es la eliminación de la ambigüedad de la forma 'su, sus', pues por lo general se ha especializado para la expresión del poseedor 'usted'. En los demás casos, en lugar de 'su, sus' se recurre a formas analíticas ('de + pronombre'). Este cambio se presenta incluso en el caso de 'nosotros'.

Es clara, entonces, la inexactitud de las explicaciones sobre los adjetivos (y pronombres) posesivos de los libros estudiados, pues todas ellas pecan de generalización de las formas usualmente consignadas en las gramáticas, posiblemente más propias del registro escrito que del oral de todas las regiones hispanófonas: en muchos lugares, 'su' no es el posesivo de 'él, ella, usted, ellos, ellas, ustedes', sino únicamente de 'usted', como se ha documentado para el habla de Costa Rica (Sánchez Corrales 1987) y de Canarias, Colombia, Ecuador, México y, en general, de América (De Granda 1978).

\subsubsection{Otros elementos gramaticales}

El libro Puntos en breve es el único que menciona otros elementos de variación morfosintáctica, algunos muy extendidos, pero altamente estigmatizados o atacados por los grupos puristas del idioma. Por ejemplo, se refiere a la tendencia en algunos dialectos de añadir una -s final en la segunda persona singular (tú) del pretérito: hablaste - hablastes; sin embargo, afirma que es preferible no hacerlo. También consigna la existencia de las formas ‘dijieron' y 'trajieron' en lugar de 'dijeron' y 'trajeron', respectivamente, pero aclara que las últimas son las aceptadas en el uso formal. También consigna 'haiga' por 'haya' en el habla cotidiana, la primera no aceptada en el uso formal. 
Asimismo, hace alusión a la pluralización de 'haber' en su significado existencial en el habla popular: "Habían muchas personas", mas añade que la forma singular es la aceptada. Lo mismo afirma de las construcciones 'me se' y 'te se' por 'se me' y 'se te' en algunas áreas rurales de América Latina y los Estados Unidos: las segundas son las aceptadas. Como se ve, aunque este libro no recomienda su uso, al menos incorpora una breve mención de aspectos muy comunes en las hablas del mundo hispánico ${ }^{16}$.

Otros elementos de variación muy generalizados no se mencionan en ninguno de los textos, a pesar de la importancia de su reconocimiento para los aprendices de español que algún día se puedan enfrentar con hablantes que los empleen: el 'hasta' exclusivo extendido desde México hasta Venezuela (Quesada Pacheco 2000a), Ecuador (Carrasco 1991) y la costa norte de Perú (Caravedo 2000), como en "Se abre hasta las 9" (a partir de las 9); el empleo de 'se los/las' por 'se lo/la' documentado en muchas de las ciudades más importantes de Hispanoamérica (México, Bogotá, Caracas, La Habana, San José, Santiago de Chile y Buenos Aires, entre otras, según DeMello 1997), por ejemplo, "Me llegó una carta. Se las voy a leer"; o el uso de 'le' por 'les' en toda América (Quesada Pacheco 2000a), como en “Le regalé varios juguetes a mis sobrinos".

Dos de estos tres últimos casos en los que los libros analizados son totalmente omisos representan buenos ejemplos de variación en los que la comprensión del mensaje puede verse perjudicada por el desconocimiento por parte de los discentes de la existencia de tales fenómenos. Un estudiante al que siempre se le han enseñado el 'hasta' con el sentido de fin o conclusión (el 'hasta' inclusivo) o el uso de 'se los' con 'los' referido a un objeto directo plural podría tener dificultades para entender los enunciados reales, pronunciados en situaciones reales con interlocutores hispanohablantes nativos reales, o pensar que o bien él no es lo suficientemente avanzado como creía o su profesor de español no le dijo toda la verdad sobre el asunto.

\section{El extremo opuesto: la diversidad incomprensible}

Al incorporar las variedades dialectales en la clase y en los materiales didácticos, también habría que evitar la sobreexposición de los alumnos a la diversidad. Es un extremo en el que es fácil caer si no se han planteado con claridad los objetivos de la actividad. Esto es, no se trata de darle al estudiante la sensación de que no podrá comprender la variedad de español coloquial de ninguna parte, pues está condenado a hablar como un no nativo en una especie de español "sin tierra". Los materiales deben estimular la tolerancia hacia la diversidad, no crear la idea de que las variedades regionales son crípticas y, por lo tanto, no merecedoras de su consideración.

Un claro ejemplo de lo que estamos diciendo se encuentra en la sección "Español a domicilio" de la revista alemana ECO, destinada a desarrollar las habilidades linguísticas en español de los aprendices germanohablantes. Aunque muy bien intencionada, esta sección peca algunas veces de presentar una visión indescifrable de la variedad, incluso para un hispanohablante nativo no perteneciente a la región estudiada. El siguiente ejemplo servirá para mostrar nuestro punto: 


\begin{abstract}
Un malón la muerte
María: Hola, ¿cómo estái?

Lorena: El descueve. Ayer estuve en un malón la muerte. Había ene gallos y gallas conocidas. Cacha, también estaba el pololo de Sofía. ¿Te acuerdas de él? El chupamedias del colegio. Lo pillé chanchito pinchando con una galla súper siútica y gansa. Y llevaba un terno súper picante. Me tinca que Sofía ni cacha que tiene.

M.: Sí, sí me acuerdo de él. La pobre Sofía. Bueno, y ¿qué había de comer y tomar?

L.: La comida estaba riquísima. Tenían hartos tipos de canapés: de loco, macha, piure, etc. Y para tomar había pisco-sour, vaina y cola de mono. Comí tanto que me dolió la guata toda la noche y llegué súper tarde a la pega, ya que no me podía levantar del sueño que tenía. Oye, ¿por qué no vienes a mi casa y aquí seguimos copuchando? Y, además, me podrías ayudar a preparar el asado para la noche. Voy a hacer unos ricos anticuchos y una buena chicha.

M.: Claro, con gusto te puedo ayudar. Pero tardaré un poco más de lo normal, ya que mi hermano chocó el auto y me toca tomar una micro o una liebre. ¿Y quién viene al asado?

L.: Ene gente. El Pelao, Pablo con su grupito, y también Claudia con su guagüita recién nacida. Tengo ene ganas de conocerla. Dicen que es un plato.

M.: ¡Qué macanudo! Así la puedo conocer también. Pero, qué lata que viene el Pelao (...)
\end{abstract}

A todas luces, el verosímil que propone el diálogo corresponde a lo que Rosenblat (1971) llama "la visión del turista": en el diálogo se destaca únicamente lo diferencial, lo extraño, al extremo de dar la sensación de estar leyendo un texto en otro idioma. Claramente, se escogieron para el diálogo los elementos más "exóticos" del habla chilena y se pusieron todos juntos, en una combinación que quizás a un hablante nativo de esta variedad le sonaría poco natural.

En otras palabras, la variación idiomática se incluye en estos materiales, pero para hacer resaltar la desviación en relación con el supuesto estándar aprendido por los estudiantes. Además de ello, obsérvese cómo la mayoría de los elementos son de tipo léxico (palabras, locuciones) y cómo los diálogos son rígidos, sin las características reales de la oralidad, o sea, son diálogos literarios (propios de, por ejemplo, una obra teatral).

\title{
4. Conclusiones: la enseñanza de la variación dialectal
}

En este trabajo nos centramos en los libros publicados a partir de la década del noventa en los Estados Unidos. Como dijimos en su momento, la decisión no fue arbitraria, sino que respondía a dos factores: el auge de la publicación de textos para la didáctica de segundas lenguas en este país (especialmente en cuanto al español) y la utilización de dichos libros en centros de enseñanza del español como L2 en Costa Rica. Es claro que el segundo factor merece una reflexión de nuestra parte: ¿por qué emplear, como libros de texto o de referencia, materiales publicados para la enseñanza del español como lengua extranjera para una población muy concreta?

La enseñanza del español en Costa Rica a hablantes no nativos corresponde a lo que se denomina la didáctica de una segunda lengua, pues aquí este es el idioma de la comunicación cotidiana y oficial en la mayoría de las regiones. No parece lógico, entonces, recurrir a textos para su enseñanza como lengua extranjera, debido a que la situación de aprendizaje es diametralmente distinta: en primer lugar, la variedad de español no corresponde a la de los libros; en segundo lugar, es posible la interacción diaria con hispanohablantes nativos que de seguro les proveerán un input mucho más rico y efectivo a los aprendices; en tercer lugar, los 
materiales didácticos para la enseñanza del español pueden elaborarse a partir de la realidad circundante (programas de televisión, periódicos, grabaciones, etc.).

Además, como ya se mencionó, estos libros están dirigidos a una población muy específica, razón por la cual casi todos ellos dan las explicaciones y los ejemplos traducidos al inglés, un elemento más para considerar la inadecuación de dichos materiales para la situación en la que se enseña el español como L2 en Costa Rica ${ }^{17}$. En todo caso, que la referencia a la diversidad lingüística sea más conveniente tratarla en la enseñanza del español como segunda lengua o como lengua extranjera es aún una cuestión por dilucidar en futuras investigaciones de campo.

Parece obvio pensar, no obstante, que la referencia a tal diversidad sea más fácil tratarla en situaciones de aprendizaje del idioma en la región donde se habla cotidianamente, por cuanto los aprendices están en contacto directo con el habla real de hablantes nativos reales en situaciones auténticas, lo cual ya de por sí conlleva a una relación con usos distintos de la lengua: los jóvenes no hablan igual que sus padres, ni las mujeres igual que los hombres, ni la variedad de la clase es la misma que se oye en las noticias o en los autobuses, etc. De esta forma, es probablemente más sencillo hacer notar a los aprendices que la lengua es heterogénea por definición, e introducir en la clase nociones breves sobre las distintas formas del léxico, la gramática, la pronunciación o la pragmática según variables geográficas, sociales y estilísticas.

Sin embargo, el hecho de que se esté enseñando español en un país donde se concebiría como lengua extranjera no justifica la promoción de la idea de que la lengua es un todo homogéneo, con reglas de acatación indiscriminada, con una gramática monolítica.

Como queda evidenciado, la ausencia (voluntaria o por desconocimiento) de explicaciones verdaderas o, cuando menos, no planteadas en términos absolutos, sobre el empleo de determinados rubros lingüísticos en español es más que patente en los libros de español como lengua extranjera examinados. Es necesario tener en mente que la mayoría de los libros pertenecen al nivel inicial de aprendizaje del idioma, pero lo cierto es que muchos estudiantes siguen estos cursos y luego, para los niveles avanzados, llevan cursos de historia, literatura o lenguaje para propósitos especiales (p.ej. español comercial), así que nunca recibirán ninguna instrucción sobre nociones de variación lingüística.

No se trata -insistamos en ello- de convertir los libros de texto en manuales de dialectología hispánica para especialistas, sino en despojarse de ciertos datos y explicaciones repetidos hasta el cansancio (pero no por esto menos falsos) sobre el funcionamiento del español, como la manida costumbre de asegurar que es en España donde se emplea tal o cual forma, sin que esto sea cierto o se haya verificado en muchos casos.

Es clara la necesidad de exponer a los estudiantes a diversas variedades del idioma con el fin de ayudarlos a desarrollar una competencia, al menos pasiva ${ }^{18}$, de sobrevivencia y alejarlos de las ideas engañosas y prejuiciadas de que existe "una forma correcta de decir las cosas" o "una única manera de emplear un determinado rubro gramatical", concepciones que, en todo caso, actúan en desmedro de la eficiencia y la eficacia comunicativa de los aprendices cuando tienen que enfrentarse al habla real (debiéramos decir, más bien, las hablas reales) de una comunidad lingüística concreta. En la enseñanza del español como segunda lengua o como idioma extranjero, vale la pena tener presente a Max L. Wagner, quien caracterizó el español de América como "variedad dentro de la unidad y unidad dentro de la diferenciación" (citado por Lope Blanch 2000). Es decir, enseñamos lo que de común tiene el sistema, pero sin perder de vista su heterogeneidad inherente a toda lengua viva. 
En este sentido, debemos insistir, como autores de libros y como profesores de español como segunda lengua o lengua extranjera, en la necesidad de incorporar referencias a la variación idiomática en aspectos tales como el voseo y el 'vosotros' en los paradigmas de conjugación y en los pronominales, en la aclaración de cuándo un elemento es propio del registro escrito o del oral (como pasa con los pronombres relativos), entre otros casos particulares ${ }^{19}$. Todo ello con el fin de no caer, en la medida de lo posible, en explicaciones excesivamente generales o falsas encubiertas con argumentos pedagógicos falaces.

Rickford (1996) señala dos razones para estudiar los dialectos en la clase de idiomas (maternos o extranjeros). El primero es preparar mejor a los estudiantes para la comprensión de las variedades vernáculas de una lengua extranjera (cabría incluir aquí también el caso de las segundas lenguas) que pueden encontrar al entrar en contacto con hablantes nativos de esta. La segunda razón es incentivar una conciencia sobre la variación social y regional del idioma, lo cual puede incrementar la sensibilidad hacia la diversidad y riqueza de las comunidades de habla en las que se emplea la lengua. En este segundo punto, es necesario hacerles notar que las diferencias dialectales son, generalmente, sistemáticas y regulares, y que no se deben a descuido o pereza de los hablantes, como comúnmente se escucha en nuestro medio. Es cierto que determinados dialectos o formas conllevan mayor prestigio, pero no es menos verdadero que esto es así como resultado de factores políticos y sociales externos a la lengua, como lo señala acertadamente el mismo Rickford.

Si hemos de concebir el español como diasistema (Sánchez Corrales 1993), en reconocimiento de su verdadera naturaleza heterogénea pero también unitaria, hemos de evitar afirmar que se está enseñando, por un lado, "el uso cotidiano de la gente educada en vez del español literario, formal” al lado que se incluye 'cuyo' como un pronombre relativo sin mencionar su desuso en el registro oral de todas las regiones -como se hace en Repase y escribay, por otro, excluir ese uso real de muchas regiones hispanohablantes y centrarse en los usos propios del registro escrito.

Es indispensable distanciarse un poco de la trillada justificación de que se está enseñando la variedad estándar. Como bien lo nota Moreno Fernández (1998), el llamado "español estándar" no está bien definido, pues en principio debería ser una variedad desprovista de cualquier elemento que no pertenezca a la generalidad del sistema; esto es, no puede seguirse identificando el estándar con la norma castellana, a partir de la cual se han elaborado los pronunciamientos académicos. Mientras no se tenga un panorama claro y definido con criterios objetivos sobre lo que sí podría considerarse un español estándar, o una norma estadística, el argumento de que determinados rubros idiomáticos (como el voseo) no deben incorporarse a la clase carece de fundamento científico.

Asimismo, habría que evitar el engaño de que, por ambientar cada lección en un país hispanohablante distinto, se está incluyendo el uso real cotidiano, cuando, por ejemplo, se conjugan los verbos en la forma 'vosotros' en los capítulos dedicados a Perú o México y se hace hablar de 'tú' a los argentinos en los diálogos supuestamente ambientados en su país (Plazas).

El problema de fondo quizás consiste en no haber definido previamente el macrodialecto que se desea o se necesita enseñar: ¿el peninsular o el atlántico? (Vila Pujol 1994) ${ }^{20}$. Por esta misma razón, en todos los libros analizados se incluye el 'vosotros' para su reconocimiento (competencia pasiva), pero pocos mencionan el leísmo también propio de las variedades peninsulares. ¿No habría que desarrollar, en este caso también, una competencia pasiva si 
hemos de ser consecuentes con nuestra propuesta? También esta es la causa de que un libro como Puntos en breve, que se caracteriza por incorporar un buen repertorio de elementos de variación en todos los niveles y con indicaciones claras del lugar donde se emplean, incluya las palabras 'computadora' y 'ordenador', sin señalar que la segunda es exclusiva de España. A todas luces, son cuestiones que no parecen haberse reflexionado en el proceso de escritura de los libros.

La propuesta de inclusión de las variedades dialectales de Vila Pujol (1994) es muy clara en indicar la necesidad de esclarecer qué se va a enseñar. Para ella, en cuanto a la cuestión primaria de si se debe enseñar la variedad del español peninsular de prestigio o el atlántico de prestigio, la decisión debe tomarse con el criterio principal del lugar donde los aprendices utilizarán la lengua. En este sentido, cobran mayor fuerza las observaciones que realizamos sobre la inadecuación de los libros de texto estadounidenses al incorporar la enseñanza privilegiada de la forma 'vosotros'.

Además del macrodialecto, Vila Pujol llama la atención sobre la importancia de incorporar referencias sobre otras subvariedades de uso geográfico más restringido, especialmente cuando se enseña español en lugares donde estas están muy diferenciadas de la que se emplea en la clase. Para ella, esta comparación entre la variedad de la clase y la variedad ambiental es necesaria para desarrollar una competencia pasiva por parte de los aprendices, de forma que estos no se sientan incapaces de desenvolverse competentemente tan pronto como salgan del aula.

Tampoco se ha reflexionado sobre la distinta frecuencia de uso de los diversos recursos lingüísticos del español de acuerdo con el registro oral o escrito. Bien lo afirma De Kock (1997: 16):

\footnotetext{
La confusión puede ser grande y los despropósitos múltiples si, en la enseñanza del español, lengua extranjera, no se llama la atención sobre las diferencias entre registros. Ni es de desear aprender a escribir el español tal como se habla -jen la realidad!- ni tampoco esforzarse en hablar como los escritores escriben. Es aconsejable, por consiguiente, mantener separados ambos registros. Comoquiera que, por razones didácticas, en la enseñanza no es sensato hacer avanzar, a un tiempo, la gramática de dos registros harto distintos, es preferible otorgar prioridad a uno de ellos.
}

Ya vimos un ejemplo claro de este defecto didáctico seudofacilitador cuando nos referimos a la inclusión del relativo ‘cuyo’ sin ninguna aclaración.

Como consecuencia de todo lo que hemos mencionado y mientras la variación idiomática no sea tomada en cuenta con toda la seriedad que amerita, a lo sumo se les seguirán presentando a los estudiantes "curiosidades dialectales", "formas exóticas" generadas, sin duda, en el calor del trópico, al margen del aprendizaje real de la lengua. Y lo más triste de ello es que tal vez ni siquiera estas sean exactas, como el epígrafe de este artículo, en el que se nos acusa a los costarricenses de encajarle las combinaciones de sufijos -ico/-ica a todo cuanto se nos ponga por el frente: comidicas, camicas y estudianticos incluidos ${ }^{21}$.

\section{Notas}

1. Esta nota dialectal de antología se la debo a mi amiga y colega Ana Elena Castillo, a quien le quedo profundamente agradecido. Deseo dejar constancia de mi agradecimiento, asimismo, al Dr. Jorge Murillo Medrano, quien tuvo la amabilidad de revisar este trabajo y sugerirme algunos cambios importantes. 
2. La lista completa de los libros examinados en este trabajo se encuentra en la segunda sección de la bibliografía.

3. Así, Quesada Pacheco (2000: 82) la consigna para el discurso religioso, mientras que Rocío Caravedo asevera que en Perú se puede escuchar en sermones, arengas y discursos y que, en todo caso, "no se trata propiamente del plural de 'tú', como forma de tratamiento no deferencial, sino más bien de una forma plural, indiferenciada respecto del tipo de tratamiento, que caracteriza situaciones solemnes o de mucha formalidad y que connota un estilo elevado no coloquial" (Alvar 2000: 162).

4. Aunque se debe notar que, al menos en la edición de 1998, faltan las conjugaciones respectivas para 'ser', 'tomar' y los verbos regulares de la primera conjugación en presente de indicativo.

5. En esta cita, y en las próximas escritas originalmente en inglés, damos una traducción libre.

6. Por otra parte, se suele ignorar el hecho de que, como afirma Quesada Pacheco (2000:86), "exceptuando las Antillas, todos los países de América presentan algún tipo de voseo y, por lo menos, en alguna de sus regiones: México (Chiapas y Tabasco), Guatemala, El Salvador, Honduras, Nicaragua, Costa Rica, Panamá (occidente), Colombia, Venezuela (zona andina), Ecuador (sierra principalmente), Perú (sierra), Bolivia, Paraguay, Uruguay, Argentina y Chile". Asimismo, hay que tener claro que el voseo no presenta los mismos paradigmas de conjugación ni recibe la misma valoración social en todas estas regiones. Al respecto, véase Lipski 1994.

7. Esta misma "libertad" para tutear en España se menciona en Horizontes como una tendencia en la actualidad a usar el 'tú' en esta nación.

8. Mención aparte hay que hacer de las regiones con un sistema tripartito: usted-tú-vos, en las que cada una de estas formas de tratamiento es adecuada según la mayor o menor cercanía entre los hablantes, como sucede en Guatemala y El Salvador. Se trata, en general, de un continuum de formalidad máxima (usted), media (tú) y mínima o nula (vos). Para más datos al respecto, véase Quesada Pacheco (2000) y Alvar (2000), entre otros.

9. Destacamos con comillas lo de tiempos verbales, pues nos ceñimos a la crítica que, con rigurosidad científica y espíritu esclarecedor, exponen del tiempo verbal en español Roja y Veiga (2000).

10. A pesar de la inexactitud de esta nomenclatura, empleo los nombres dados por el Esbozo de una nueva gramática de la lengua española (1973), no porque me parezcan acertados, sino porque son los más conocidos en nuestro medio.

11. Valga aclarar que en Dos mundos, por ejemplo, a todas luces se trata del valor típicamente hispanoamericano de esta forma. Lo mismo habría que decir de Puntos en breve.

12. En un estudio particular al respecto, Moreno de Alba (1977a) resalta el uso más restringido de esta forma verbal en México frente a su alta frecuencia de empleo en España, tanto en el registro oral (10,2\% de uso del perfecto compuesto, frente a $45,1 \%$ del imperfecto y $41,9 \%$ de perfecto simple), como, en general, también en el registro escrito hispanoamericano (8,9\% frente a 39,3\% en las obras de Benavente).

13. Sin embargo, Moreno de Alba (1977a) cita el trabajo estadístico de Bull sobre el español hispanoamericano, en el que se exponen los siguientes porcentajes: $2,26 \%$ en el registro escrito y $0,98 \%$ en el registro oral (porcentajes sobre el total de formas verbales empleadas). A simple vista se nota el reducido empleo del futuro sintético también en la escritura.

14. Menciono este factor como uno de tantos posibles todavía no investigados. Mi impresión es que, en Costa Rica al menos, el uso de la forma con -se podría estar motivado por la formalidad que el hablante quiere imprimirle a su discurso. 
15. Tampoco parece acertada, al menos no para todos los dialectos peninsulares, la explicación de que 'ese' tenga un valor despectivo. Para el español de Córdoba, Diana Ranson (Serrano 1999) describe valores muy diversos de este y los otros demostrativos, aun cuando van pospuestos, posición para la cual Gili Gaya había declarado su significado peyorativo. De Kock (1997) afirma que, para el habla culta de Madrid, 'ese' no tiene ninguna connotación despectiva.

16. De hecho, es bastante insistente en incluir notas sobre aspectos del español del suroeste de Estados Unidos, como la existencia de 'nadien/naidien' por 'nadie' y 'muncho' por 'mucho'.

17. Una anécdota puede servir para ejemplificar mejor este problema. En una mesa redonda en la que se presentó una primera versión de este trabajo, una asistente intervino para relatar que, al entrar a un chat francés en el cual alguien preguntó cuál era el mejor país de América Latina para aprender español, los participantes le indicaron que en cualquiera daba lo mismo, pues de todos modos en todos se empleaban libros de texto en inglés hechos en Estados Unidos, así que lo mejor era buscar el país que fuera más barato.

18. Ciertamente, se supone que, en la enseñanza de segundas lenguas, se persigue una competencia activa. Sin embargo, creo que el dominio activo de muchas variedades idiomáticas regionales no debe ser un objetivo de la didáctica de lenguas, no solo porque implicaría una labor agotante y hasta contraproducente, sino porque ni siquiera es común que un hablante nativo de una lengua domine todas sus variedades. El ideal de enseñanza de las lenguas (maternas o segundas) debería ser -en nuestra concepción- la tolerancia, respeto y comprensión de la mayor cantidad posible de variedades regionales y sociales, y la competencia activa en varias modalidades estilísticas.

19. Si bien hemos señalado aquí algunos de sus problemas, Plazas, Dos mundos y Puntos en breve constituyen buenos ejemplos de textos que se preocupan por la inclusión de diversos elementos de variación.

20. No es que exista una descripción detallada de estos dos macrodialectos señalados por Vila Pujol, pero sí parece acertado tomar esta distinción como punto de partida. En términos lingüísticos, contamos con isoglosas generales que nos permitirían contraponerlos: en gramática, la inexistencia de la forma 'vosotros' en el paradigma verbal y pronominal de uso cotidiano en el español atlántico; en fonología, el seseo de esta misma macrorregión. Si partimos de estos dos hechos, por lo menos, tendremos una idea sobre qué pronunciación y cuáles modelos de conjugación verbal enseñar. En todo caso, la cuestión de las macrovariedades no es de fácil resolución; sobre todo si se recuerda la polémica discusión sobre la distinción entre español americano y español peninsular.

21. Aquí es indispensable realizar una última aclaración. Es propio de muchos dialectos caribeños la disimilación fonética del sufijo diminutivo -it. Esta disimilación se da cuando la raíz de la palabra termina en /t/, razón por la cual la [t] del sufijo cambia a [k] (escrito «c»). Así, 'gatito' se diría en muchas regiones 'gatico'. En Costa Rica, este fenómeno parece haber tenido mucha mayor extensión y empleo décadas atrás, aunque todavía muchos hablantes, especialmente mayores o de zonas rurales, realizan la disimilación. En el habla de las generaciones más jóvenes, subsisten algunas formas como 'poquitico'. Según algunos autores, el antiguo uso ampliamente extendido de las formas diminutivo-cariñativas (con -it o con -ik) en el habla costarricense es el motivo de que se nos conozca con el gentilicio de 'ticos' (principalmente por el antiguo apelativo de 'hermanitico') (Gagini 1975). Sin embargo, un costarricense nunca usaría las formas 'camica' o 'comidica', pues no cumplen con el requisito de presentar una [t] final en la raíz. Es más que obvio el desconocimiento de la realidad lingüística costarricense del que escribió tal nota dialectal. 


\section{Bibliografía}

\section{Bibliografía de referencia}

Alvar, Manuel (dir.). 2000. Manual de dialectología hispánica. El español de América. Barcelona: Ariel.

Bosque, Ignacio y Violeta Demonte (eds.). 1999. Gramática descriptiva de la lengua española. Tres tomos. Madrid: Espasa Calpe.

Caravedo, Rocío. 2000. “Perú”. En Alvar (dir.).

Carrasco, Félix. 1991. “La variante mexicana de 'hasta’: perspectivas diacrónicas sincrónicas”. En: Hernández (ed.).

De Beaugrande, Robert. 2000. "La saga del análisis del discurso”. En: Van Dijk (comp.).

De Granda, Germán. 1978. Estudios lingüísticos hispánicos, afrohispánicos y criollos. Madrid: Gredos.

De Kock, José y George DeMello. 1997. Gramática española: Enseñanza e investigación. Lengua escrita y habla culta en América y España. Salamanca: Ediciones Universidad de Salamanca.

Donni de Mirande, Nélida. 2000. “Argentina”. En: Alvar (dir.).

Gagini, Carlos. 1975. Diccionario de costarriqueñismos. San José: Editorial Costa Rica.

Garrido Domínguez, Antonio. 1992. Los orígenes del español de América. Madrid: MAPFRE.

Hernández, César (ed.). 1991. El español de América I. Salamanca: Publicaciones Junta de Castilla y León.

Lee McKay, Sandra y Nancy H. Hornberger (eds.). 1996. Sociolinguistics and Language Teaching. Cambridge: Cambridge University Press.

Lipski, John. 1994. El español de América. Madrid: Cátedra.

Lope Blanch, Juan Manuel. 1970. Estudios sobre el español de México. México: UNAM.

(ed.). 1977. Estudios sobre el español hablado en las principales ciudades de América. México: UNAM.

2000. “México". En: Alvar (dir.). 
Miguel, Lourdes (ed). 1994. Cuadernos del tiempo libre. "Didáctica del español como lengua extranjera". Madrid: Fundación Actilibre.

Moreno de Alba, José. 1977a. "Frecuencias de formas verbales en el español hablado en México". En: Lope Blanch (ed.).

1977b. "Vitalidad del futuro de indicativo en la norma culta del español hablado en México". En: Lope Blach (ed.).

1994. El español en América. México: Fondo de Cultura Económica.

Moreno Fernández, Francisco. 1998. Principios de sociolingüística y sociología del lenguaje. Barcelona: Ariel.

Quesada Pacheco, Miguel Ángel. 2000a. El español de América. Cartago: Editorial Tecnológica de Costa Rica.

2000b. “América Central”. En: Alvar (dir.).

Rickford, John R. 1996. "Regional and social variation”. En: Lee McKay (ed.).

Robins, R. H. 1997. Breve historia de la Lingüística. Madrid: Cátedra.

Rojo, Guillermo y Alexandre Veiga. 2000. "El tiempo verbal. Los tiempos simples.” En: Bosque y Demonte (eds.), 2867-2934.

Rosenblat, Ángel. 1971. Nuestra lengua en ambos mundos. Navarra: Salvat Editores.

Sánchez Avendaño, Carlos. 2001. "Desuso preposicional ante cláusulas de relativo en el habla culta costarricense". Káñina. XXV (1): 113-122.

Sánchez Corrales, Víctor. 1987. "La ambigüedad como mecanismo del cambio lingüístico: Ejemplos del español de Costa Rica”. Revista de Filología y Lingüística. XIII (1), 163-166.

1993. "La incorporación del español de América a la enseñanza del español como lengua extranjera o como segunda lengua". En: Solano (comp.).

Sedano, Mercedes y Paola Bentivoglio. 2000. "Venezuela". En: Alvar (dir.).

Serrano, María José (ed.). 1999. Estudios de variación sintáctica. Madrid: Vervuert.

Solano Rojas, Yamilet. 1990. Los nexos en el habla culta costarricense. Tesis de Doctorado, Universidad Nacional Autónoma de México. 
Solano Rojas, Yamilet (comp.). 1993. Memoria V Congreso de Filología y Lingüística. San José: Ed. Guayacán.

Van Dijk, Teun (comp.). 2000. El discurso como estructura y proceso. Barcelona: Gedisa.

Vaquero Ramírez, María. 1998. El español de América II. Morfosintaxis y Léxico. Madrid: Arco Libros.

Vila Pujol, M. Rosa. 1994. "Dialectos, niveles, estilos y registros en la enseñanza del español como lengua extranjera”. En: Miguel, Lourdes (ed.).

2. Textos de español como lengua extranjera estudiados

Ascarrunz Gilman, Graciela y Marian Zwerling Sugano. 1993. Horizontes. Gramática y conversación. Boston: Heinle \& Heinle Publishers.

Borrás A., Guiomar. 2000. Spanish for Business Worktext. Boston: Heinle \& Heinle Publishers.

Brown, Carol y Kathleen Moore. 2000. Spanish for life. Boston: Heinle \& Heinle Publishers.

Canteli Dominicio, María y John J. Reynolds. 1998. Repase y escriba. Curso avanzado de gramática y composición. Nueva York: John Wiley \& Sons, Inc.

Caycedo Garner, Lucía, Debbie Rusch y Marcela Domínguez. 1993. ¡Claro que sí! Boston: Houghton Mifflin Company.

Dawson, Laila M. y Albert C. Dawson. 2001. Dicho y hecho. Beginning Spanish. Nueva York: John Wiley \& Sons, Inc.

Hershberger, Robert. 2001. Plazas. Lugar de encuentro para la hispanidad. Boston: Heinle \& Heinle Publishers.

Humbach, Nancy y Oscar Ozete. 1996. ¡Ven conmigo! Austin: Holt, Rinehart and Winston.

Iorillo, Nino R. y Andrés C. Díaz. 1996. Conversación y controversia. Nueva Jersey: Prentice Hall.

Jarest, Jackie y Marsha Robinson. 1990. Charlemos un poco. Boston: Heinle \& Heinle Publishers.

Levy-Konesky, Nancy y Karen Daggett. 2000. Así es. Orlando: Harcourt Brace \& Company.

Martín Peris, Ernesto, Neus Sans Baulenas y Julia Caballero Martín. 2003. Gente. Nueva Jersey: Pearson Education. 
McVey Gill, Mary, Brenda Wegmann y Teresa Méndez-Faith. 1999. En contacto. Gramática en acción. Orlando: Holt, Rinehart and Winston.

Ozete, Óscar. 2001. ¡Saludos! Orlando: Harcourt College Publishers.

Ozete, Óscar y Sergio D. Guillén. 1987. Contigo. Essentials of Spanish. Nueva York: Holt, Rinehart and Wiston, Inc.

Pérez-Gironés, Ana María y otros. 2002. Puntos en breve. Nueva York: McGraw-Hill.

Renjilian-Burgy, Joy, Ana Beatriz Chiquito y Susan M. Mraz. 1999. Caminos. Boston: Houghton Mifflin Company.

Terrell, Tracy D. et al. 1998. Dos mundos. Nueva York: McGraw-Hill.

Woodford, Protase E. y Conrad J. Schmitt. 1995. A bordo. Nueva York: Macmillan/McGrawHill.

Zayas-Bazán, Eduardo y Susan M. Bacon. 2001. ¡Arriba! Comunicación y cultura. NewJersey: Prentice-Hall. 